\title{
THE RELATION OF LAW TO EXPERIMENTAL SOCIAL SCIENCE
}

\section{By Thomas A. Cowan $\dot{T}$}

"In medicine all the sciences grouped round the art of treatment had to be liberated from the commercial casuistry of the profession before sound biology and scientific pathology could produce hygiene and preventive medicine. In the same way, in law, the jurisprudent must first of all free himself from the trammels and impediments of expediency, and then perhaps he will be able to build up an effective technique of safeguards against possible breach and incentives to good citizenship." 1

Malinowski's analogy is instructive. It is well-known that as the biological sciences became experimental they separated off from the art of treatment, were developed in the laboratory quite apart from immediate application, and entered medicine proper as applied science. The result is that modern medicine has progressed further in the last hundred years than in all the previous millennia during which the art of healing had engaged the sustained attention of the human race. Jurisprudence today is in a position comparable to that which medicine occupied a century ago. That is, it is a hodge-podge of science, philosophy and technical art. The books are full of references to the "science of law," the "philosophy of law," and to the various aspects of the technical legal process.

It is the purpose of this paper to suggest that the familiar tripartite division of jurisprudence should undergo change. In brief, it is the writer's position that the "science of law" should become a part of an expanded social science as the latter is placed more firmly on an experimental basis. An attempt will also be made to indicate very briefly at the end of the article how philosophy of law should merge with philosophy of the social sciences, or as this last subject is coming to be called, the methodology of the social sciences. ${ }^{2}$ The result to be anticipated from these developments, of course, is a vast enrichment of the third part of jurisprudence, that is, the technical legal art, law proper, with "legal science" and "legal philosophy" as we know them today things of the past. This is a very large order indeed. It calls for a certain amount of "crystal-gazing" if we are to be able to

$\dagger$ B. S., 1926, LL. B., 1931, Ph. D., 1932, Univ. of Penna.; S. J. D., 1933, Harvard; Professor of Law, Wayne University.

1. B. Malinowski, Introduction to Hogbin, LAW AND ORder IN PolyNesia LXVIII (1934).

2. See, for example, Kaufmann, Methodology of the Soctal Sciences (1944). 
discern something of the dim outline of the jurisprudence of the future. The effort will be worth while if it does no more than indicate new areas and lines of research.

We shall begin then with the statement that law stands to social science in some sense as medicine stands to biological science. This view assumes that neither law nor medicine is science. Rather each is a body of applied scientific learning; a focus round which clusters, to greater or less degree, a curious admixture of science, myth, superstition, folklore, and the traditional practices of centuries-old craft. It has been the homely wisdom of the ages that only the priesthood could compete with medicine and law in encysted isolation from current progressive notions and in stout resistance to change under impact of the science of the day. For the past century, however, medicine has broken sharply with tradition and has incorporated more and more of the results of the experimental sciences. The term "scientific medicine" has become a barbarism, since "non-scientific medicine" is now recognized as magic or superstition. How goes it with law? Why are the terms "science of law" or "scientific law" not recognized as solecisms?

It is perhaps unnecessary to emphasize that these conceptions should be recognized as outmoded. That they are in fact not so regarded is made abundantly clear by a reference to almost any modern work on jurisprudence. Indeed, the conviction that law is a science, or that the body of legal materials is or should be a scientific corpus is well-nigh universal. Idealists and empiricists alike share this conviction. From the starry idealism of the Kantian Stammler ${ }^{3}$ or the mystic Radbruch, ${ }^{4}$ through the double way of the life of reason and faith of the neo-Scholastics, ${ }^{5}$ to the present day phenomenologism of Kelsen ${ }^{6}$ and his followers runs a common assumption that an idealist basis for an autonomous science of law exists or can be made to exist. The same is true for the empiricists past and present. Whether it be John Austin's ${ }^{7}$ dry-as-dust narrow analysis of the body of the matured systems of modern law or Roscoe Pound's ${ }^{8}$ multi-faceted system of

3. Stamimler, Systematrsche Theorie der Rechtswissenschaft (1923); LeHrBUCH DER RECHTSPHILOSOPHIE (1928); Fundamental Tendencies in Modern Jurisprudence, 21 Mich. L. Rev. 623 (1923).

4. RADBRUCH, RECHTSPHILOSOPHIE (3d ed. 1935).

5. Geny, Methode d'INterpretation en Droit Prive Positif (2d ed. 1919); Science et Technigue en Droit Prive Positif, vol. I (1913), vol. II (1915), vol. III (1912), vol. IV (1924).

6. Kelsen, Reine Rechtslehre (1934); Kelsen, General Theory of Law and State (Wedberg's trans. 1945) ; EBenstein, The PURE Theory of LAW (1945); 55 HARv. L. Rev. 44 (1942); 51 L. Q. REv. 517 (1935); 50 L. Q. Rev. 474 (1934).

7. AUUSTIN, JURISPRUDENCE (1911).

8. Pound, The Scope and Purpose of Sociological Jurisprudence, 25 HARv. L. REv. 140 (1912); Fifty Years of Jurisprudence, 50 HARv. L. REV. 557 (1937) ; 51 HaRv. L. REv. 444, 777 (1938). 
sociological jurisprudence ${ }^{9}$ embracing as it does the newest conceptions of pragmatism, the assumption is always implicit and generally expressed that law should be a science coordinate with the other sciences and that the central problem of the student of jurisprudence is to lay the foundations of a modern science of law. The only serious challenge to this widely-held conviction is the negativistic attack of the sceptics whose efforts are largely directed to exposing the pretensions of legal "scientists" and "philosophers." This work, while a necessary propedeutic, must not be left to stand alone. For it leads to cynicism and frustration, and experience indicates that rather than remain indefinitely unsatisfied with sceptical "solutions," most people end by returning to an even more intrenched position of dogmatism.

Suppose we take it for granted for the moment, then, that the "science of law" is still permitted to flourish because social science has not absorbed it; and that this absorption has not taken place because social science is not experimental enough. On this assumption, law can aid the development of an emerging social science in two ways. First by preparing to accept as much as possible of the newer developments of these embryonic sciences; and second (but this is only an extension of the first) by so formulating its own body of doctrine that the social sciences will be stimulated to research and will be encouraged to meet the demands of an expanding system of law for more and more intensive development of the science of society.

Let us now examine a few instances to illustrate the effects of the developing social disciplines on law. If we turn to anthropology we can see in short compass the effect of prevailing legal theories on field investigations and the correlative influence of such investigations on law after the inadequacies of legal theory become manifest. Under the influence of English and continental doctrines of the nature of law based on analysis of matured systems, amateur anthropologists (usually missionaries) were.able to report an almost total absence of law in primitive society. ${ }^{10}$ The simple savages, unrestrained by the onerous bonds of legal obligations, were supposed to have worked out the affairs of their everyday lives in happy innocence reminiscent of the golden days of the Garden of Eden. With the development of positivism, however, and the growth of the notion that the foundation of the legal system is the body of restraints imposed by political or social authority as the outgrowth of custom, the pendulum swung the other way, and

9. See Pound, Sociology of Law and Sociological Jurisprudence, 5 U. of Toronto L. J. 1, 2-3 (1944): "Sociological jurisprudence is in another line of development. It proceeds from historical and philosophical jurisprudence to utilization of the social sciences, and particularly of sociology, toward a broader and more effective science of law."

10. See Malinowskx, Crime and Custom in Savage Society 11-12 (1926). 
the primitives were conceived as a group of tradition-bound law-ridden wretches, too ignorant to break through the "cake of custom" to a more progressive life. ${ }^{11}$ Both views were, of course, one-sided and inadequate, stemming from narrowly conceived theories of the nature of law. When, therefore, stimulated by a pragmatic theory of knowledge, anthropology broke with the legal tradition and commenced to investigate the jural relations of primitive communities as they actually function, ${ }^{12}$ a counter influence on jurisprudence was set up with salutary effects on legal thinking. It is now no longer fashionable in legal circles to speak of fundamental principles of law governing the whole of human society. In anthropology, the field worker now knows that the data on law which one gets from an investigation of a primitive society is conditioned by the jural assumptions and postulates he takes with him to the investigation. ${ }^{13}$ In other words, anthropologists have reached the Kantian stage in the study of law and by comparison legal theories often seem unsophisticated.

All primitive tribes still extant are undergoing a process of acculturation ${ }^{14}$ as a result of the impact of modern civilization. These changes are the subject of investigation by modern anthropologists who are able to observe the effects of modern systems of social control on native ways of life. One of the most important aspects of such control is, of course, law. Studies by Malinowski ${ }^{15}$ and his school show the actual effects to be observed from different types of control imposed by colonial administrators on so-called primitive peoples.

More elaborate than these, and more in accordance with scientific methodology are the researches of Kardiner, ${ }^{16}$ Dubois ${ }^{17}$ and others. Working toward designed experiments incorporating psychoanalytic techniques, these investigators are attempting to set up "controls" in

11. Id. at 9-10.

12. For examples of functional analysis of law in non-literate societies, See HogBIN, note 1 supra; Llewellyn AND Hoebel, The Cheyenne WAY (1941).

13. See, for example, Malinowski, A Scientrfic Theory of Culture 7 (1944): "As I shall try to point out, a genuine scientific method has been inherent in all historic work, in all chronicling, in every argument used in jurisprudence, economics, and linguistics. There is no such thing as description completely devoid of theory. Whether you reconstruct historic scenes, carry out a field investigation in savage tribe or a civilized community, analyze statistics, or make inferences from an archaeological monument or a prehistoric find-every statement and every argument has to be made in words, that is, in concepts. Each concept, in turn, is the result of a theory which declares that some facts are relevant and others adventitious, that some factors determine the course of events and others are merely accidental by-play; that things happen as they do because personalities, masses, and material agencies of the environment produced them."

14. Hersh kowitz, Acculturatron: The Study of Culture Contact (1938).

15. Malinowski, The Dynamics of Culture Change (1945); The Present State of Studies IN Culture Contact, Africa, Vol. xl (1938), Vol. xii (1939); Hogbin, Experiarents in CiviLization (1939).

16. Kardiner, The Indrvidual and His Socrety (1939); The Psychological. FrontIERS OF SocIETY (1945).

17. Du Bois, The People of Alor (1944). 
the scientific sense. They seem to be groping toward a newer and more significant notion of what a "social laboratory" should be and their results, if they can be developed, should be of vast importance to law.

In the field of psychology, we need only note how much of the law of evidence has come into wide disrepute by the general realization of the gross unreliability of witnesses in testifying even to the simplest facts. Our famed jury trial was a device which gradually substituted rational examination of evidence for the mechanical trials of an earlier period. These early systems had been rigid, formal, crude. Their evident effect was to settle disputes on the basis of agreed upon ritualistic performances irrespective of the merits of the controversy as we would see those "merits" today. Compared with these ceremonies, jury trials were scientific. Now, however, we must admit that the all too frequent result of trials is the ceremonious disposition of controversies without serious attempt to discover scientifically the facts which form the basis of the dispute.

Thus far, the finding of psychology as to the reliability of testimony has had only a negative effect on the law. We have had demonstrated for us beyond cavil that the senses, which once were thought of as the only reliable source of knowledge of the outside world, are quite unreliable. To be sure, this is merely scientific confirmation of an opinion stoutly held on the basis of common sense and of philosophic doctrine since Greek times. Now. however, we have highly developed mèthods for measuring deviations sfrom a norm of sensitivity in stimulus, and response in the field of isensations. ${ }^{18}$

A half century of experimental work on the organs of sight, sound, taste, smell and touch has accumulatedla sophisticated body of doctrine concerning bodily sensations. But onl a small fraction of this learning is serviceable to the law. What the evidence expert is really interested in is not so much the reliability of the nowers of observation of witnesses, but rather their general credibilitv. To repeat, common sense is well acquainted with the fallihility of the organs of sensation. Indeed, the etymological distinction lbetween "common sense" on the one hand, and your "sensations" andlmine on the other shows that this conviction is deeply rooted in the language. General credibility is much more than this. It is the answer to the question: What accounts for the fact that different individuals give different degrees of assent to one and the same proposition? Its answering involves among other things a way of measuring degrees lof assent. We know now that the problem is vastly more complicatedl than the eighteenth and nineteenth

18. Cowan, Credibility, Probability, find Social Science, 4 Burc. Instrutute of Experimental Method 18 (1947). 
century mathematical statisticians took it to be. The studies of Nicholas Bernouilli, Laplace, Condorcet, Poisson, and Quetelet are interesting examples of how very naive much of the work of genius may appear to informed lay opinion of a later era. ${ }^{19}$ Nevertheless, what for them was the result of inspiration must become for our psychologists hard work. The beginning of a psychology of general credibility is at hand. It takes the form of an attempt to put on an experimental basis the study of human personality. ${ }^{20}$ In this field, law is in the position not so much of accepting advances in psychology as of demanding that psychology devise credibility scales so that some of the fruits of this science of the future may be available to it.

The development of psychoanalysis and its "deviates" is having a potent though often undiscerned effect on legal theory. This fundamental re-orientation of the nature of the human mind brings into prominence the unconscious as distinguished from the conscious aspects of mental behavior. And as might be expected all disciplines based upon the assumption that only conscious behavior fully deserves the description "mental" must, as this new viewpoint makes headway, recast their foundations. It is inviting to speculate on the effect this new insight could have on the law's theory of mental behavior. In the Psychopathology of Every Day Life, Freud advanced the theory that all slips of speech and of memory, however "accidental" they may appear, really serve some unconscious purpose. The notion of "unconscious intentions" is given meaning and the forceful analogy between the mind and the iceberg is suggested. That is, it is intimated that only a small fraction of mental behavior reaches the level of consciousness. Much the most important part remains submerged, inaccessible to the individual, and open only to "analysis" by the expert.

The idea of "unconscious intention" as applied to the legal notion of intent is interesting. As now constituted intent in law refers to conscious purpose. What does negligence mean? Why, evidently "unconscious purpose." Negligence is not absence of a state of mind, but presence of unconscious purpose of an anti-social character. This notion interpolates a third possibility between the theory of subjective (conscious) intent of the classical variety, and the theory of objective intent of the Holmesian mold. Each of these as presently constituted is unsatisfactory. Subjective intent is largely abandoned except in the criminal law while objective intent reduces the actor to an automaton, rewarded for mechanical obedience to legal rule, punished equally mechanically for infraction thereof. 
Psychoanalytical knowledge is becoming very widespread as a result of keen interest on the part of the general public in the workings of the unconscious mind. Doubtless other instances of its possible effect on the law can be readily supplied by the reader. The law of evidence, for example, is bound to feel its effects some day. Criminal administration is in the thick of it, at least at the medical end of the subject. The criminal law itself, not only in the case of crimes of a sexual nature, but in other crimes as well could conceivably be reorganized on a "psychoanalytical" basis. In fact the whole subject of reform respecting crime and punishment could well advance beyond the stage of outraged protest of novelists and humanitarians and be placed in a scientific setting as a study in sado-masochism. Thus viewed, the criminal law and its administration would be regarded as a branch of medicine rather than law. Then treatment could be substituted for force, the law could be spared the brutalizing effect of resort to physical coercion in its most hideous form, and humanitarian judges could really dispense justice, that is, the settling of disputes on a rational peaceable basis.

In the realm of politico-legal theory, the old quarrel as to whether law takes its sanction from morality (often called "the law of nature") or whether on the contrary all law is nothing other than the command of the political sovereign could receive from psycho-analysis a reorientation that would outmode completely the older formulation of the problem. Conscience re-appears as the super-ego. Account could then be taken of the evidence, becoming overwhelming, that the habits of obedience to law and order are internalized commands of such potency and vigor as to make negligible by comparison the claim that behind every law and alone efficacious for its observance is the political power of the state. One who obeys too much, too readily, is a neurotic! In this formulation the voice of conscience (the super-ego) as the foundation of the legal order reasserts itself over the notion, now become academic, that only the external force of society guarantees obedience to the law.

The psychoanalytic insight that the use of force, brutalizing alike to victim and "avenger," is always some form of sado-masochism throws light on one of the most harrowing dilemmas the law has to face. For undoubtedly law is society's alternative to war, the supreme instance of the resolution of controversies on the basis of sadomasochism. But when the law too resorts to force, the sadism and the masochism merely change their form. They still remain pathological. Hence, the perversity of those legal theorists of the analytical school who insist that the very foundation of law and its sole sanction is the 
politically organized force of society. As well say, law is society's politically organized sado-masochism. This change of perspective would insist that the "force" aspect of analytical jurisprudence recognizes itself as pathological, that is, a lamentable condition to be cured if possible.

In social psychology, experimental work shows the persistence of native habits of observance or violation of rules of behavior. ${ }^{21}$ For example, apparently no known correlation exists between the response of law observance or violation on the one hand, and legal stimulus in the form of the criminal law on the other. Interests or psychological drives, which now are the foundation of law for the pragmatists, notably Pound, call for a social psychology to carry legal theory further on. The day is coming when consultation with the social psychologist will be a necessary pre-requisite to legislation designed as most of it is to regulate human behavior in conflict situations.

In economics, Marxism as well as non-Marxian views of the nature of human society have had a revolutionary effect on legal theories. Under the materialistic attack on the exploitative character of human society and the laying bare of the conflict of interests among various groups, the older ideal of the law as the expression of eternal principles of justice, above class and creed alike, gave way to newer interpretations of law as the expression of the various interests, economic, political, social, religious in the community. This type of analysis often of the order of exposé or (more shallowly) debunking, rests on the position that the legal order as now imperfectly constituted exists to arbitrate differentially the conflicting demands of the various classes in society. This is a frank recognition that the interests of the community are not homogeneous, that they do in fact conflict. We might take as an example of the above the following "stylized," "hypothetical" or "composite" interpretation of the materialistic view. Let us assume that in the period during and immediately after a successful revolution, for example, the interests of all important sectors of the ranks of the insurgents are united against a common externalized enemy. When, however, the harmony of purpose born of the revolution is over and counter-revolutionary activities are no longer to be feared, the source of conflict is recognized as internal. Government assumes the role of arbitrator, expands the scope of its activities, makes justiciable more and more controversies, and grows in bulk.

If and when internal conflict becomes wide-spread and the economy threatens to be disrupted, government assumes a more active role and provides social service to meet the rising demands which 
the non-governmental economy cannot fill. Then law needs a complete re-orientation. Its adversary method of settling disputes no longer suffices. The executive branch of the government is dominant and law becomes executive, that is, administrative. Once more exposé becomes popular. For in a class society the administration of positive services cannot be impartial. One class is served at the expense of another. What one gets, the other must do without. Administrative law, the response of the legal order to the needs of a service government, cannot avoid laying bare the conflict of interests among those who compete for its services. By the materialistic view, administrative law (in its widest possible sense) must pave the way for its own destruction since it contains within itself the seeds of contradiction. Either it becomes judicial justice on the basis of purported attempts to deal impartially with controversies, in the outcome of which it has no interest; or else it is forced openly to betray itself as the instrument of a particular class and disappears from law into the general economy as a service agency devoid of legal character.

The above is but a brief illustration of many possible materialistic interpretations of the relation of law to the economic structure of modern society. Theories of the economic character of law rise and fall with the ebb and flow of general theories of economics.

Thus far we have been interested in the effect of social science on law. The reciprocal effect of law on social science will be analogous. The present body of doctrine, developed by those having a joint interest in law and some branch of social science likewise awaits the emergence of genuine experimental science. The studies known as psychology of law, ${ }^{22}$ sociology of law, ${ }^{23}$ legal anthropology, ${ }^{24}$ as well as the even more diffuse bodies of learning called law and statistics, ${ }^{25}$ law and economics, ${ }^{26}$ law and politics, ${ }^{27}$ and the like, will presumably all be subsumed under the aegis of experimental social science.

22. Britt, The Lawyer as the Psychologist, 36 InL. L. Rev. 621 (1942), The Social Psychology of Laz, 34 ILl. L. Rev. 919 (1940); FRANK, LAW AND THE MODERN MIND (1930).

23. Pound, Soctology of Law, Twentieth Century Soctology (1945) ; Gurvitch, Sociology of LaW (1942) ; Ehrlch, Fundamental Principles of Sociology of LAW (Moll's trans. 1936); TimashefF, AN INTROduction to the Soctology of LAW (1939).

24. Malinowski, $A$ New Instrument for the Interpretation of Law, 51 YaIE L. J. 1235 (1942) ; Hoebel, Fundamental Legal Concepts as Applied in the Study of Primitive Law, 51 Y ALE L. J. 951 (1942); note 12, supra.

25. Jaffin, Prologue to Nomostatistics, 35 CoL. L. Rev. 1 (1935).

26. Robinson, Law and Economics, 2 Mod. L. Rev. 257 (1939); STONE, THE Province and Function of Law 607-609 (1946); Commons, Legal Foundations of CaptTalism (1924) ; Arnoln, The Symbols of Government 72-104 (1937).

27. Frankfurter, Law and Politics (1939) ; Laski, Studies In Law and PoliTICS (1932); Pound, Law and the State-Jurisprudence and Politics, 57 HARv. L. REv. 1193 (1944). 


\section{An Example From the Law of Evidence}

So far we have been dealing with over-all effects of the reciprocal impact of law and the social sciences. In this section we turn to an attempt to show in what way these views of the relation of law to social science could affect and influence a particular branch of the law, namely the law of evidence.

The dependence of any branch of "evidence" upon science is obvious to modern readers, and the close connection between any branch of the law, including the law of evidence, and morality is likewise readily admitted. But what of aesthetics? What is its connection with the law of evidence? Why, evidently, aesthetics deals with art, whether fine art or technical art. And the law (at least the law in action) is a technical art, and the rules of evidence are a most important part of the law's technique. Hence, aesthetics must ultimately be taken account of in any thoughtful consideration of the nature of the law of evidence.

Morality makes its demands on the law of evidence by virtue of the fact that the primary end of the law of evidence, as of all law, is to secure the just settlement of conflicts. And settlements are generally not deemed to be just unless they accord with the long-range scheme of values the community and the culture prizes. But one of the values most highly prized by the present culture is "scientific truth." Occasionally the demands for the recognition of this value become so exigent that they subordinate all other values for the time being. Finally, the ensemble of the ways in which conflicting values compete and find their resolution is the art of judicial administration; and the rules of evidence (indeed all procedural devices) have much to say about how this art shall be practiced.

To press this notion a little farther: art (technical art) deals with form, style, manner of doing things. It too is a value. Skill, craft, technique are "good." Thus, into the conflict of values between norms of just decision and standards of truth must also go the claims of skill, craft, and technique. We have mentioned the fact that on occasion the demands of science are recognized as paramount. Justice and art yield to truth; sometimes gracefully, and then the decision is often discovered in fact to be both just and artful; sometimes with manifest reluctance, and then we should be on guard lest the decision is either not just or not technically sound.

Again, strange to say, "justice" may take the center of the stage, subordinating truth and art. The outcome may well be a fortunate one-perhaps truth and art should yield, that "justice may prevail." But perhaps on the contrary, demands urged in the name of justice do 
such violence to truth or to art that injustice in fact results. The balance must be restored, for a morality that outruns one of its prime values, truth, is apt to be tyranny. To outrun another of its values-skill, art-is to defeat in action its own ultimate purpose.

Lastly, the demands of art may quite evidently dominate to the exclusion of the others. If the outcome is well and happily founded, older notions of truth and justice may be expected to yield. If not, then we may well suspect that art, craft, technique (let us now call the result "ceremony") have sacrificed either justice or truth on their altar.

This much said it is time to reflect that despite its apparent newness, the methodological question of the relation of art, science and morality to the law of evidence is really old, as such things go. Particularly is this true with reference to science and morality. The basic outlines of the problem were laid down half a century ago in Thayer's Preliminary Treatise on Evidence. ${ }^{28}$

Thayer undertook the pioneering task of precipitating the law of evidence out of the complex substances which had theretofore held it in solution. His job was to trace the origin and development of the jury system as the efficient cause of the law of evidence; to mark law off from fact in order to make plainer the functions of judge and jury; and (as concerns us here) on the one hand, to show the difference between legal proof and proof in general, and on the other to distinguish the body of the rules of evidence from the whole process of legal reasoning or proof. So well and carefully was this work of delimiting the proper area of legal evidence done and so pressing was the necessity for doing it, that it is perhaps not too much to say of this patient and subtle legal analyst that he created the modern law of evidence.

Two notions of paramount importance stand out in his exposition of the nature of legal reasoning. These are first that "legal reasoning" is an art whose primary function is to seek justice, not truth; and second that despite this accommodation of a mental process to a particular end, the art of reasoning and the laws of thought remain constant for legal as well as for all other human pursuits. Such a "functional" or "pragmatic" view of the nature of reasoning runs counter, of course, to all modern rationalistic views of truth as autonomous, and therefore unaffected by social purpose. For Thayer, it is clear, truth is something that exists "for a purpose"; and, in law, this purpose is evidently justice. And still this leaves us with the dilemma of "legal reasoning" unresolved. Is reasoning an autonomous activity of the mind or is it not? If reasoning is a constant then (1898).

28. Thayer, A Preliminary Treatise on Evioence at the Common Law 
how can it be subordinated to justice? Is "legal reasoning" merely a convenient label to designate the particular activity at which the mind is directed? No, legal reasoning or more specifically legal proof is meant to be a body of doctrine which can be studied by itself. Indeed, the task of studying is taken by Thayer as representing a challenge to legal scholarship that cannot be indefinitely deferred. ${ }^{29}$

Wigmore had high hopes that the science of judicial proof would soon displace the rules of admissibility, although ironically enough his own life work was dedicated to the rules and his writings on science of proof remained substantially unchanged as they first appeared in 1904. ${ }^{30}$ For example in the Introduction to the Principles of Judicial Proof (1913) he writes:

"The judicial rules of Admissibility are destined to lessen in relative importance during the next generation or later. Proof will assume the important place; and we must therefore prepare ourselves for this shift of emphasis." 31

What contribution, we may now ask, can the social sciences make to the problem of the nature of judicial proof. It has already been intimated that the clarification to be hoped for is the relation of science to ethics. Certain of the social sciences (particularly if one includes psychology among them) are more interested in the question of truth. Others, notably anthropology, deal with human institutions as a whole and their learning throws light on the judicial process as an agency of social control. The play of truth against justice, of science versus morality, of proof as a means and the just settlement of disputes as the end of the legal process-all are illustrated in the development of the various branches of the science of man in society.

Let us lift out of its context an example of the right of private retaliation in primitive justice as related by Hogbin in Law and Order in Polynesia.

"Perhaps the most remarkable case on record is that of a husband who killed, not the adulterer, but his brother. This brother was a notoriously bad lot, while the adulterer himself was a popular man. The relatives took no action, probably being glad to be rid of him."

This is as extreme an instance as one could well imagine of the ethical sense of the community being satisfied without any heed paid to, indeed in obvious defiance of, the "truth" concerning the identity of the wrongdoer. It is not that in primitive communities the truth

29. Id. at 273 .

30. Compare 1 Wigmore, Evidence $\$ 30$ (1st ed. 1904) with Wigmrore, Principles of JUdictal Proof, 5 (1913), and with 1 WIGMORE, EVIDENCE $\$ 30$ (3d ed. 1940).

31. Wigarore, Introduction to the Principles of Judicial Proof (1913). 
is not a matter of "judicial" concern. It is. But different cultures rate "truth" differently in their scale of values, and if one wishes to push the inquiry far enough he finds that what is taken to be "true" or what is taken to be "evidence" varies from culture to culture, and presents the social scientist with some of the knottiest problems he has to deal with. ${ }^{32}$ Thus it can be said that for the tribe in question, the "true" criminal was the brother of the adulterer, on the theory of familial responsibility and a doctrine which we might label "respondeat inferior."

In Hoebel's study of the Political Organization and Law-Ways of the Comanche Indians, ${ }^{33}$ we find that among these peoples there seems to have been no overt recognition of the problem of evidence, except in sorcery.

"The crux of the procedure was bargaining. There was no question of evidence-except in sorcery. In the damage-seeking cases the evidence was obtained before action was brought. In wife-absconding cases the presence of the woman with the absconder was prima facie evidence which need go no further. In all our cases but one the bargaining was begun with guilt accepted by both parties. In cases of adultery, beyond in flagrante delicto, evidence came from witnesses or by confession of the wife. However it may be, except for cases of sorcery, there was no technique for obtaining evidence from the defendant. Nor was the defendant usually confronted with witnesses. The aggrieved had to ascertain to his own satisfaction who the guilty party might be. After this had been done the defendant could then be confronted."

"And what if guilt was denied? Usually it was not. When the defendant refused to own up, the procedure apparently came to an impasse. The aggrieved might be angry enough to take illegal steps (violence), or he might possibly kill some of the accused's horses to satisfy his desire for damages. The latter course would be likely to lead to retaliation, however, for the defendant, in denying guilt, denied cause for damages and such peremptory taking of damages was to him illegal. The reaction of the defendant if the first recourse were taken by his accuser is problematical; it would depend pretty much on his temperament and guilt in fact. Denial of guilt by an accused (except in sorcery) was so uncommon that there are not cases enough to draw sound conclusions." 34

This does not mean of course that the individual litigant was not confronted with the problem of "proving his case." It means, rather, that unless the matter were one of common repute, the "law" of the

32. Sherif, Psychology of Social Norms, Chaps. I-II (1936).

33. Memorrs QF the American Anteropological Association, No. 54 (1940).

34. Id. at 53-54. 
community afforded no redress. The question was beyond "the limits of effective legal action," and the individual was left to his own resources without "political" or community help. Of course, if the modern investigator is so inclined, and if the materials are available, an inquiry into doubtful cases could be undertaken and the results, perhaps, carefully generalized.

In the always doubtful case of sorcery among the Comanches for example, evidence was an ever present problem, for in sorcery the "act of aggression was secret and the aggressor a dangerous person." The techniques developed for evidencing sorcery were, with these people, either some form of ordeal or torture (to test a wife's fidelity).$^{35}$

We have nothing to learn from the Comanches, or from any other primitive people, respecting the legal use of ordeal or torture and hence these evidentiary techniques in themselves are of no special consequence. What is important, however, is the process by which the investigator is seen to piece together creatively a system of law out of the undifferentiated social behavior of a primitive people. Not only must he look carefully for instances of proof processes, but unless he possesses in advance of his investigation a fairly well developed notion of the function of legal evidence, he is likely to discover nothing on the subject. If, on the other hand, he does possess a conceptual frame-work, results may be forthcoming, but they are as apt as not to require adjustment of the frame-work which often is seen to rest on too restricted a notion of the nature of law and of its constituent elements. Certainly, if the rules of evidence be confined to notions of scientific proof in the modern sense, then the conclusion could easily be forced that primitive peoples could possess no "law of evidence." But if a comparative study of the effect of social norms on what is taken to be proof is desired, then the investigation of the habits of primitive people in settling controversies is invaluable as a way to check against our own cultural biases in the field of the law of evidence.

Moreover, these anthropological studies throw light upon the law of evidence in revealing the fondness of the primitive mind for mechanical solutions in determining disputed matters of fact. Our law of evidence abounds in vestiges of such mechanical solutions. Even where the ends of justice are otherwise sought in refined and sophisticated methods, the evidence rules serve as a hamper on adequate investigation of the truth. Let us take the hearsay rule as one example of this process.

The dispute on the origin and function of the hearsay rule centers first about whether it is a device to safeguard the probative value of 
testimony (science) or whether on the contrary the rule originates and persists in a desire to safeguard the fairness of judicial procedure, the right of cross-examination (justice). Thayer originally subsumed the hearsay under the Best Evidence rule.

"The objection to hearsay, then, goes, fundamentally, to the point that something which should come through an original witness is sought to be put in at second hand, by one to whom it has been told, one who it not a witness properly speaking, who did not perceive it and cannot therefore testify to it, but only to the fact that someone said so." ${ }^{38}$

Thayer, for whom the primary purpose of the judicial process is the just solution of cases (not the ascertainment of truth) regards the hearsay rule as going to the question of probative value.

Wigmore regards the hearsay rule as the result of the operation of a fundamental characteristic of the system of the common law: the right of cross-examination. Ostensibly, for Wigmore, the rule excluding hearsay is a device that safeguards the probative value of testimony, and the right of cross-examination has as its foundation the same fundamental purpose.

Nevertheless, it seems rather evident that the right of crossexamination does not have the discovery of truth as its main purpose, nor need truth ever be anything but its incidental result. ${ }^{37}$ For, inasmuch as the right of cross-examination is not a requirement or a duty to cross-examine, but an opportunity to cross-examine, it remains as a privilege of the party against whose cause the witness is testifying. Evidently the opportunity to cross-examine goes to the question of fairness to the adversaries. Truth waits on the purposes of the crossexaminers. Indeed the fundamental caveat of every cross-examiner is to beware of strengthening his opponent's case by eliciting damaging truths from an adverse witness. In sum, Wigmore, staunch supporter of the science of judicial proof really defends the hearsay rule on the basis of justice and fair procedure. To admit hearsay is to deprive the party (unfairly) of his opportunity to cross-examine.

In the American Law Institute's Model Code of Evidence (Professor Morgan, Reporter) we have a return to the view which really regards the hearsay rule as a probative device, and since the device does not operate effectively to this end, a virtual though somewhat artificial proposal for its abandonment. The whole of the Introductory Note to Chapter VI on Hearsay Evidence looks at the rule only from the point of view of its probative value. ${ }^{38}$ The view there

36. Thayer, A Preliminary Treatise on Evidence at the Common Law, 501 (1898).

37. See discussion of MODEe CoDe of EvIDENCE (1942) infra.

38. Id. at 217 et seq. 
taken is that the hearsay rule arose as a result of change of the common law mode of trial from an investigative to an adversary process. The bulk of the exceptions to the rule can be explained, on this view, only by the adversary method of trial, for there is nothing in their nature to prevent cross-examination. Those who purport to find in the exceptions substitutes for cross-examination are said to be "rationalizing." 39 Without offering the adverse party any substitute for their loss of the opportunity to cross-examine, the writers of the note, we may infer, would have them consoled with the reflection that their loss is rather small in any event and that the real probative value of hearsay would, again we may presume, far outweigh it socially.

We can see in this review of conflicting doctrines the clash and mixture of the two ideals, truth and justice. Yet, the hearsay rule is an intolerably mechanical restriction on the ascertainment of truth and only of very doubtful value in preserving the fairness of the adversary mode of trial. Its primitive character is evident in its rule-of-thumb distinctions between propositions of competing probative value, and in its all-or-nothing nature respecting included or excluded testimony.

The above analysis could be made of other exclusionary rules. The writer ventures the opinion that to the extent that they are designed to guarantee the probative force of certain classes of evidence they are out-moded, and this not because of the jury system nor the adversary nature of the common law mode of trial, but simply because common consciousness of the way to prove things has advanced to the point where the methods of exclusion become gross and mechanical, and refinements and exceptions become mere tinkering. The exclusionary rules are based on an outmoded science and morality, and their results in modern practice are therefore highly "artificial."

\section{Philosophy OF LAW}

There is one large branch of legal science not heretofore alluded to. I refer to what is often called formal science of law or legal logic. The subject is in reality a part of scientific methodology and as such has the closest possible connection with philosophy. And this brings us to the second part of the paper, the philosophy of law and its relation to social science.

It is a truism that when a body of knowledge becomes experimental it breaks off from philosophy and becomes an independent domain of inquiry. Thus, physics and chemistry used to be known as natural philosophy; psychology, as mental philosophy; and sociology, social philosophy. The degree of emancipation of any discipline from

9. Id. at 222. 
philosophy is measured by the extent to which its study is put on an experimental basis.

It is not hard to understand, therefore, why law has always had a direct and immediate connection with philosophy and why the history of legal theories in modern times is a record of the rise and fall of philosophical doctrines. Each new philosophic creed finds ready application to law and it is safe to say, I think, that no modern philosophical system exists which does not have as an integral and prominent part of its thought a well-developed philosophy of law. ${ }^{40}$

At the beginning of the modern era, ${ }^{41}$ the philosophical system known as rationalism assumed that the basis of knowledge lay in the immediate apprehension of a few fundamental principles, known by the exercise of reason alone, that serve as the postulates from which all detailed knowledge might be deduced. In its wake developed a full fledged rationalistic jurisprudence. The fundamental principles of law were assumed to be known to reason, and the positive enactments of law followed from those by a process of rigid deduction. That these principles turned out to be the common notions inherited from the Roman law simply meant that history confirmed what reason was sure of.

The eighteenth century empiricists evolved a contradictory theory of evidence. Facts alone can be known immediately. Principles follow from them by a process of induction. The application of this theory of evidence to law is immediate. Jurisprudence must collect facts and by a process of analysis extract from them legal principles. Analysis of actually existing legal materials suffices for the development of a science of law. The problems of legal reform, or investigations into the purpose and end of law, are extra-legal pursuits.

Kantian philosophy attempted a synthesis of these two views. Some principles can be known $a$ priori, the rest by experience. Facts are apprehended immediately, but knowledge can arise from them only in the light of an a priori framework of principles. Formal science is separated from empirical science and by the co-operation of each knowledge arises. Kantian legal doctrine found its place in this synthetic philosophy and the present day Kantian legal systems are modifications, whether slight or profound, of the original Kantian philosophy. They are all based on the assumption that a pure science of law can be developed quite apart from experience.

Of all modern philosophical systems, modern theories of law owe most to the Hegelian system of thought. Not only the insight

40. Pound, Outlines of Lectures on Jurisprudence, 197-204 (1945).

41. See the writer's article on Legal Pragmatism and Beyond, in INTERPRETATIONS of Modern Legal Philosophies, 131 (1947). 
that all facts are social, and with them, therefore, all legal facts, but also the teaching that all facts are fluid and depend for their meaning on their historical conditioning, as well as their present context, are owed to Hegel, and the legal learning of the nineteenth century pays tribute to this huge obligation in specific and numerous borrowings from the Hegelian storehouse.

Positivism contributed largely to the jurisprudence of the last century. Its disdain for completed systems, its insistence on centering attention upon the factual situation to the exclusion of theoretical constructs and its emphasis upon positive law, whether decision, legislation or executive degree, are well-known influences in the law.

Finally, when we come to the present century we see emerging as the dominant philosophical system the doctrine of pragmatism. This theory insists that beyond and beneath legal forms are human interests pressing for recognition. Law comes to be regarded as an agency of social control, one among many. How well law succeeds in its task is the measure of its success. If the purposes which law exists to achieve are effectuated, well and good. If not, law must be moulded and shaped to attain these ends. The idea of law as an abstract system of justice or as a body of commands to be obeyed simply because expressed by a sovereign will is a thing of the past. Legal philosophy becomes a theory of interests ${ }^{42}$ and social psychology takes up where law leaves off. ${ }^{43}$

Not alone pragmatism, of course, but the ragtag and bobtail of all other philosophical creeds that enjoy current favor find their counterparts in systems of legal philosophy. Transcendental idealism, neoscholasticism, economic and psychological determinism, all conceivable shades of positivism, logical and otherwise, as well as various eclectic and synthetic systems flourish in the dark waters of modern jurisprudence. The one philosophical system not well represented in jurisprudence is the philosophy of experimentalism, ${ }^{44}$ a condition not hard to understand because not until social science becomes truly experimental can law take its proper place as applied science or practical art. ${ }^{45}$

Although the philosophy of experimentalism can be said to have no past so far as law is concerned, since the philosophy has itself had no past, one may be pardoned for looking to the future to see what will

42. Pound, $A$ Survey of Social Interests, 57 Harv. L. Rev. 1 (1943).

43. Stone, op. cit. supra note 26 , at 673-785.

44. See Singer, ON the Contented LIFe (1936); Mind as Benavior (1924); EXPERIENCE AND REFLECTION (to appear) ; Philosophy of Experiments, THE SYMposium, Vol. 1, No. 2 (1930); ChurchMan, Theory of ExperIMIENTAL INFERENCE (to appear).

45. Cowan, supra note 41 , at $140-142$. 
or should be the relation of experimentalism to law and the social sciences. Experimentalism views the philosophy of science as methodology. It studies the general conditions under which experiment may most fruitfully be undertaken. It divides methodology into two parts, formal and material, and combines both parts into a system called design of experiment. ${ }^{4 b}$ It believes that only the well-designed experiment can have the most fruitful results, and it attempts to make the experimenter conscious of the difference between the presuppositions he takes with him to his investigations and the data he gets from the subject of the experiment. It is a fundamental assumption of experimentalism (though by no means confined to it alone) that only through experimental methods can a body of learning now advance significantly. When a given area of scientific inquiry fails to make significant advance, this philosophy assumes that its experiments are not well designed and undertakes to discover the methodological causes for the failure.

Experiments in social science are notoriously unsatisfactory. The experimenter in this field is not prepared to assert with any degree of confidence what are even the broadest requirements of a social experiment although he feels intuitively that it differs in some profound way from the laboratory experiments of the physical sciences. He knows that the laboratory is not the proper place for social experiments because it is abundantly clear that laboratory control makes the social situation artificial. And yet, if the laboratory is given up, how can the experiment be controlled? Is it too far-fetched to suggest that the social scientist's "control" is law, or some aspect of law? Law is undoubtedly a mode of social control, the most nearly conscious method by which projected social results are forcibly brought about. I suggest that one aspect of the solution of the social scientist's quest for control lies in law. As was suggested at the outset, legal philosophy should become part of the philosophy of the social sciences.

This thesis can receive no more than mere assertion at this time. Its weaknesses must be apparent to all. Yet I believe it contains a core of truth, that this truth will grow and that with its growth, law and theory of government can take their places as true parts of the body of science, not restricted as they now are, to the "trammels and impediments of expediency," but "liberated from the commercial casuistry of the profession" and free to nourish, and in turn to be fructified by, the beneficent influences of a science of society worthy of the name social science.

46. Fisher, Design of Expertarents (1937). 